\title{
BM] Global Health Factors influencing undernutrition among children under 5 years from cocoa-growing communities in Bougainville
}

\author{
Jessica Hall (D) , ${ }^{1}$ Merrilyn Walton, ${ }^{1}$ Floris Van Ogtrop, ${ }^{2}$ David Guest, ${ }^{3}$ \\ Kirsten Black, ${ }^{4}$ Justin Beardsley (iD ${ }^{5}$
}

To cite: Hall J, Walton M, Van Ogtrop F, et al. Factors influencing undernutrition among children under 5 years from cocoa-growing communities in Bougainville. BMJ Global Health 2020;5:e002478. doi:10.1136/ bmjgh-2020-002478

Handling editor Sanni Yaya

Received 17 March 2020

Revised 17 June 2020

Accepted 7 July 2020

Check for updates

(c) Author(s) (or their employer(s)) 2020. Re-use permitted under CC BY-NC. No commercial re-use. See rights and permissions. Published by BMJ.

${ }^{1}$ School of Public Health, The University of Sydney, Sydney, New South Wales, Australia

${ }^{2}$ School of Life and

Environmental Sciences, The University of Sydney, Sydney, New South Wales, Australia

${ }^{3}$ Sydney Institute of

Agriculture, School of Life and Environmental Sciences, The University of Sydney, Sydney, New South Wales, Australia ${ }^{4}$ Obstetrics, Gynaecology and Neonatology, The University of Sydney, Sydney, New South Wales, Australia

${ }^{5}$ Westmead Clinical School, The University of Sydney, Sydney, New South Wales, Australia

Correspondence to

Jessica Hall;

jessica.hall@sydney.edu.au

\section{ABSTRACT}

Half the children under the age of 5 years in Papua New Guinea (PNG) are undernourished, more than double the global average with rural areas disproportionately affected. This study examines factors associated with stunting, wasting and underweight in cocoa growers' children ( $<5$ years) in the Autonomous Region of Bougainville (ARoB), using data from a comprehensive 2017 cross-sectional livelihoods survey. Sixteen independent predictors for stunting, wasting and underweight were selected based on the UNICEF Conceptual Framework of Determinants of Undernutrition. We used multilevel logistic mixed regression models to measure the association of the explanatory variables with stunting, wasting and underweight. At the household level, the adjusted $\mathrm{OR}(\mathrm{aOR})$ of stunting $(\mathrm{aOR}=1.71,95 \% \mathrm{Cl} 1.14$ to 2.55 ) and underweight $(\mathrm{aOR}=2.11,95 \% \mathrm{Cl} 1.16$ to 3.82$)$ increased significantly among children from households with unimproved toilet facilities. The $\mathrm{aOR}$ for underweight also increased among children from households without access to clean drinking water $(\mathrm{aOR}=1.97,95 \% \mathrm{Cl} 1.19$ to 3.29$)$. Short maternal stature was significantly associated with child stunting, the odds increased as maternal height decreased (from 150 to $<155 \mathrm{~cm}, \mathrm{aOR}=1.52,95 \% \mathrm{Cl} 1.02$ to 2.26 ) $(<150 \mathrm{~cm}, \mathrm{aOR}=2.37,95 \% \mathrm{Cl} 1.29$ to 4.35$)$. At the individual level, the odds of a child being underweight increased with birth order (second born, aOR=1.92, 95\% $\mathrm{Cl} 1.09$ to 3.36; third born, $\mathrm{aOR}=6.77,95 \% \mathrm{Cl} 2.00$ to 22.82). Compared with children less than 6 months, children aged 6-23 months and 24-59 months had a higher odds of being stunted ( $\mathrm{aOR}=3.27$, $95 \% \mathrm{Cl} 1.57$ to 6.78 and $\mathrm{aOR}=2.82,95 \% \mathrm{Cl} 1.40$ to 5.67 ) and underweight $(\mathrm{aOR}=4.83,95 \% \mathrm{Cl} 1.36$ to 17.24 and $\mathrm{aO} \mathrm{R}=4.59$, $95 \% \mathrm{Cl} 1.29$ to 16.26$)$. No variables were found to be significant for wasting. Interventions that simultaneously target key life stages for women and children and the underlying social and environmental determinants are required for sustained improvements to undernutrition.

\section{INTRODUCTION}

Child undernutrition is a leading contributor to death and disability globally. It is responsible for nearly half the deaths in children less

\section{Key questions}

What is already known?

- Undernutrition increases the risk of child morbidity, mortality, poor cognitive development, chronic diseases in adults and reduced human and economic productivity.

- Papua New Guinea (PNG) has among the worst nutrition outcomes for children $<5$ years of age globally, and there is limited current evidence on specific drivers of undernutrition in PNG and the Autonomous Region of Bougainville (ARoB).

- Cocoa farming, PNG's third largest export and the primary livelihood for Bougainville, continues to have low productivity levels and labour shortages. Poor health and nutrition are thought to be contributing factors.

What are the new findings?

- Only study assessing factors associated with child undernutrition within the $\mathrm{AROB}$ and broader islands region of PNG.

- Water and sanitation are key factors associated with undernutrition among children $<5$ years in Bougainville.

- Short maternal stature $(<150 \mathrm{~cm})$ increased the odds of a child being stunted by 2.37 times compared with the tallest maternal height group $(\geq 155 \mathrm{~cm})$.

- Children $\geq 6$ months had a higher odds of being stunted and underweight compared with children $<6$ months.

What do the new findings imply?

- Improving nutrition outcomes and the livelihoods of cocoa-farming communities in Bougainville requires holistic, interdisciplinary interventions that simultaneously target critical life stages for women and children and the underlying social and environmental determinants.

- These new findings provide a necessary evidence base for developing tailored policies and interventions aimed at improving the nutrition, health productivity and overall livelihoods of smallholder cocoa-farming families within Bougainville. 
than 5 years of age, ${ }^{1}$ with a disproportionate burden in low-and-middle-income countries (LMICs).

Undernutrition is detrimental to individuals, households and the broader community. Undernourished children have an increased risk of mortality, are more likely to suffer a childhood illness, be cognitively impaired, perform poorer in school, have lower earning potential and carry higher risks for non-communicable diseases in later life. ${ }^{2}$ These effects of poor nutrition start in utero and span generations. Undernourished women have a higher risk of giving birth to low birthweight babies, who in turn have a higher risk of suboptimal growth and development. ${ }^{3}$

The $\mathrm{WHO}$, in response to this evidence, set goals to reduce the number of stunted children by $40 \%$ and to maintain childhood wasting to less than $5 \%$ by $2025 .^{4}$ These goals have been further reinforced by the second Sustainable Development Goal. ${ }^{5}$

Determinants of undernutrition have been well documented in the literature. The UNICEF Conceptual framework for causes of malnutrition categorises these determinants into immediate (dietary intake and disease), underlying (household food security, care and feeding practices, unhealthy household environment and inadequate healthcare services) and basic causes (geographical location, lack of capital and resources). ${ }^{6}$

While good progress has been made in reducing the level of child undernutrition globally, progress has slowed down in the Asia-Pacific region, where over half the world's malnourished children live. ${ }^{7}$ Papua New Guinea (PNG) has the highest prevalence $(65 \%)$ for combined stunting, wasting and overweight. ${ }^{8}$ Similar to other LMICs, undernutrition remains a greater burden in the more populous rural areas of PNG, ${ }^{9}$ where smallholder farming continues to be the main source of livelihood. Being one of the most ethnically diverse countries in the world, the environmental conditions, cultural practices and diets vary greatly between geographical areas. ${ }^{9}$ This heterogeneity calls for a better understanding of the context-specific drivers of poor nutrition within subpopulations.

To further this understanding, we administered a large cross-sectional household survey with cocoa-farming communities in the Autonomous Region of Bougainville $(\mathrm{ARoB})$, a rural and remote island province of $\mathrm{PNG}$. The ARoB endured a decade long conflict between 1988 and 1998 which decimated local health and education infrastructure. Many people today are without access to basic healthcare, clean water and sanitation-open defecation is common, ${ }^{1011}$ a behaviour which Spears reported could account for a large portion of the variation in child height internationally. ${ }^{12}$

Two-thirds of the ARoB population are smallholder cocoa farmers. ${ }^{13}$ Cash crop farmers face a number of risks and uncertainties related to productivity such as unstable market prices, pests and diseases and the increasing threat of severe weather events associated with climate change. ${ }^{14-16}$ In the ARoB, this has been exacerbated by sustained low levels of cocoa productivity in the years following the conflict. Efforts to improve farming practices over the years have not been fully realised. It is thought that this may be caused by poor uptake and underlying constraints within the local community. ${ }^{17}$ While a range of factors can influence cocoa production, our research suggests that high levels of poor health and nutrition play a considerable role in the ARoB. ${ }^{11} 13$ Similar links have been drawn by other studies involving smallholder cocoa farmers. ${ }^{15} 18$ Persistent poor health and nutrition are major factors underpinning farmers' capacity to improve cocoa yield, sales and income. Conversely, a reduced income may limit access to nutritious foods and healthcare, leading to poorer nutrition and health. ${ }^{13}$ Many cocoa-farming communities own livestock $(61 \%)$ that share living spaces-this increases the risk of faecal-oral transmission of pathogens to humans. Repeated infections over time are associated with poor nutrition and growth of children. ${ }^{19}$ The challenges faced by smallholder cocoa farmers are complex and multifactorial, requiring the knowledge and skills from multiple disciplines.

This study is part of a larger 6-year ACIAR funded project (HORT/094/2016) which uses a One Health approach to enhance cocoa farmer productivity and livelihoods by assessing and addressing the health of the farmer, cocoa tree and the environment. A One Health approach involves transdisciplinary teams working together to improve health outcomes for humans, animals and the environment in which they inhabit. ${ }^{20}$ Details of this approach are outlined in a separate paper. ${ }^{21}$

Despite the known links between health, nutrition, labour availability and productivity being known, ${ }^{22}$ many agriculture development programmes to date have been discipline-centric with focus on improving farming practices via technology. Without simultaneously addressing the health, nutrition and environmental needs of the farming communities, improvements in productivity will be limited. ${ }^{17}$ Understanding the nutritional status and identifying factors associated with poor nutrition are a key component to improving livelihoods of cocoa farmers in the ARoB.

Although PNG has some of the highest rates of child undernutrition in the world, there is scarce research into the specific drivers of poor nutrition within PNG. ${ }^{923}$ Geographical location, particularly rural residence, has been shown to be significantly associated with child undernutrition in PNG. ${ }^{24-26}$ At the household level, poorer household wealth, ${ }^{24}{ }^{27}$ inadequate water supply and overcrowding, ${ }^{27}$ lower maternal education, ${ }^{27-29}$ poorer asset ownership of mothers ${ }^{30}$ and lower education level of household head ${ }^{24}$ were reported to be significant. At the individual level, Olita'a et al found younger maternal age, low birth weight, short birth interval and incomplete vaccination were significant factors. ${ }^{27}$ Due to a paucity of PNG data, many of these studies used older datasets, which may not reflect the current context. To the best of our knowledge, no other study has assessed 
Box 1 Principles for selecting participating villages

Village must identify as a cocoa-growing community.

- Village must demonstrate motivation and leadership to participate in study.

- Villages selected must cover a geographically diverse area and include remote areas.

- Villages selected for the study should include those that have and have not previously received support.

- Study sample should complement other projects on the ground and avoid duplication.

Village should have potential for farming diversification.

the multilevel tactors associated with cnild undernutrition within the ARoB or the broader islands region of PNG. Therefore, our research aims to provide an understanding of the nutritional status and key factors associated with undernutrition among children under 5 from cocoa-growing communities in the ARoB.

\section{METHODS}

\section{Data source and sampling method}

We conducted a cross-sectional household survey across three regions of Bougainville-North, Central, Southover a 12-month period in 2017. A census of households was implemented in 33 purposively selected village assemblies (VAs), 11 from each of the three regions. A VA comprises two or more villages. A total of 2348 households were sampled from the 33 VAs. Only 24 households did not participate in the study due to respondents not being home at the time of interview, severe illness and a small number did not want to participate. Villages were purposively selected by our in-country team members using the principles detailed in box 1 .

Information was captured at both household and individual levels (men $\geq 15$ years, women aged 15-49 years and children under 5). Anthropometric measurements were captured for women 15-49 years (approximately reproductive age) and children under the age of 5 years.

The survey used a combination of validated questionnaires (UNICEF MICS, USAID DHS, WHO World Health Survey) and comprised six modules: Household, Men (15 years+), Women (15-49years), Children (under 5 years), Women's Anthropometric (15-49years) and Children's Anthropometric (under 5years). Questions were translated into Tok Pisin and piloted. Trained interviewers administered the survey using CommCare, a mobile data capture application on android tablets. CommCare enables data to be captured offline in the field and uploaded to the server at a later time when internet connectivity was available. Interviewers were also trained in performing routine anthropometric measurements. Interviews were conducted at the household in a private location, consent was obtained at the time of interview. Further details on the livelihood, survey is documented in a formal report (https://tadep-png.com/wp-content/ uploads / 2020/04/Report-on-the-Results-of-a-Livelihood-Survey-of-Cocoa-Farmers-in-Bougainville.pdf).
Of the 2531 women aged 15-49 years eligible for interview, $1911(75.5 \%)$ were successfully interviewed, with $1796(70.1 \%)$ measured for weight and height. Information captured included demographics, socioeconomic status, birth history, maternal and newborn health, women's health and anthropometric measurements.

Of the 1384 children less than 5 years old eligible for measuring, we measured the height and weight for 1281 $(92 \%)$. After cleaning and merging all the separate data files together, 1104 children were included in the analyses. Of those 1104 children, complete and valid data were captured for height and age from 1009 children, weight and height from 1033 children, and height and age from 1068 children. The nutrition indices were analysed separately and only children with complete data were included.

\section{Variables}

\section{Outcome variables}

The primary outcome for this study is undernutrition in children under 5 years. Three widely accepted anthropometric indices-height-for-age (stunting), weight-for height (wasting) and weight-for-age (underweight)-are used to assess nutritional status. Team members used stadiometers to capture the height (24-49 months) and recumbent length ( $<24$ months) to the nearest $0.1 \mathrm{~cm}$ for those children less than 5 years. SECA scales with digital displays were used to measure weight to the nearest $0.1 \mathrm{~kg}$. $\mathrm{Z}$ scores for height-for-age (HAZ), weight-for-height (WHZ) and weight-for-age (WAZ) were calculated using the 2006 WHO Child Growth Standards. ${ }^{31}$ All anthropometric indices were analysed as dichotomous variables: 0 , normal if $Z$ score $\geq-2 S D ; 1$ (stunted, wasted, underweight) if $Z$ score $<-2 S D$.

Height-for-age is a measure of linear growth. A low height-for-age or stunting reflects failure of a child to reach his or her full growth potential due to chronic poor health and or nutrition. ${ }^{32}$ Stunting is largely considered irreversible after the first 2 years of life, and as such, the interpretation varies depending on a child's age. Stunting in a child less than 2-3 years indicates a child is failing to grow, whereas stunting in an older child means he or she has failed to grow. ${ }^{32}$

The weight-for-height is a measure of body weight in relation to height. In comparison to stunting, weightfor-height is a reflection of recent or severe weight loss often associated with severe deficiency in calorie intake or illness. $^{32}$

Weight-for-age is a measure of body weight in relation to age and reflects both chronic and acute malnutrition. ${ }^{32}$

\section{Explanatory variables}

Sixteen independent variables were included. These variables were selected after reviewing the literature and the UNICEF Conceptual Framework of Determinants of Undernutrition ${ }^{6}$ and categorised into three main groups: community characteristics, household characteristics and 
Table 1 Independent variables included in the multilevel mixed logistic regression models for stunting, wasting and underweight

\begin{tabular}{ll}
\hline Level & Variables \\
\hline Community & Village assembly \\
Household & No. of household members \\
& Wealth index \\
& Food security \\
& Drinking water source \\
& Condition of toilet facilities \\
& Maternal education \\
& Paternal education \\
& Maternal age at birth \\
& Maternal height \\
& Maternal BMl \\
& Birth order \\
& Sex of child \\
Individual & Age of child \\
& Had diarrhoea in 2 weeks prior \\
& Ever breastfed \\
\hline
\end{tabular}

BMI, body mass index.

individual characteristics. Variables included in the analysis models are listed in table 1.

\section{Community characteristics}

VA was included as a predictor to assess whether place of residence was a significant risk factor for child's nutritional status.

\section{Household characteristics}

A household wealth index was constructed from an inventory of household (radio, television, DVD player, mobile phone, watch, refrigerator, electricity), transport (bicycle, motorbike, car, truck, canoe, motorboat), productive assets (agricultural tools, fishing gear rice mill, 4wheel tractor) and livestock ownership (pig, chicken, goat, other) using principal component analysis. ${ }^{33}$ Households were then ranked according to their scores and split into wealth quintiles, each group equating to approximately $20 \%$ of the population.

Household food insecurity was measured using the Household Food Insecurity Access Scale (HFIAS), developed by the Food and Nutrition Technical Assistance (FANTA) project. ${ }^{34}$ The scale relates to three domains of food security access: anxiety about the households' food supply, insufficient food quality (variety and preference) and insufficient food intake. ${ }^{34}$

Other household variables include number living in the household, highest education level of parents (primary or lower, high school or higher), maternal age at birth ( $>40$ years, 30-39years, 20-29years, <20years), maternal height $(\geq 155 \mathrm{~cm}, 150$ to $<155 \mathrm{~cm},<150 \mathrm{~cm})$, maternal body mass index $(\mathrm{BMI})\left(\mathrm{kg} / \mathrm{m}^{2}\right)$ : underweight $(<18.5)$, normal $(18.5$ to $<25)$, overweight $(25.0$ to $<30)$, obese $(>30)$. Main drinking water source and type of toilet facilities were categorised as improved or unimproved using the classification adopted by the WHO/
UNICEF Joint Monitoring Programme for Water Supply and Sanitation. ${ }^{35}$

\section{Individual characteristics}

Child's sex, child's age $0-5$ months (exclusive breastfeeding), 6-23 months (appropriate complementary feeding) and 24-59 months, birth order (first, second, third born), whether the child had ever been breastfed and whether the child had experienced diarrhoea in the past 2 weeks were all included in the individual level group.

\section{Analysis}

Data analysis and manipulation was conducted using $\mathrm{R}$ Studio V.1.2.1335 and R V.3.6.0. Most of the variables analysed had complete data due to the way in which information was captured and validated using a digital platform. Any missing variables were excluded from the analysis. The data were checked for inconsistencies and outliers were removed prior to analysis. For example, children and women with abnormal date of birth were excluded. Children were also excluded from the analysis if their Z scores fell outside the WHO Child Growth Standards plausible range ( $\mathrm{HAZ}<-6$ or $>6$, WHZ $<-6$ or $>5$, WAZ $<-5$ or $>5) .{ }^{31}$ Descriptive statistics were used to generate frequencies to summarise and explore the variables. This was followed by an exploratory bivariate analysis to compare each of the variables by the three study outcomes of stunting, wasting and underweight (results not shown). To take into account the hierarchical nature of the data, multilevel multivariate logistic mixed regression models were used to analyse factors associated with stunting, wasting and underweight at the individual, household and community levels. Clustering at regional, VA and household was captured in the random component of the model. We initially compared a null model with a nested (Household ( $\mathrm{HH}$ ) within Village Assembly (VA) within Region (R)) random component with different combinations of $\mathrm{HH}$, VA and R using Akaike's information criteria (AIC). The lowest AIC was found when only VA was included as a random component. Therefore, all future models were run including only VA as a random effect as adding $\mathrm{R}$ and $\mathrm{HH}$ had little impact on model outcomes in terms of inference. Three models were constructed for each study outcome. Model 1 was an empty model without predictor variables to capture variation at the VA level. Model 2 included household level factors. For model 3, significant household level factors were added to the individual level factors. The median odds ratio (MOR) was calculated at each level to assess the effect of VA on stunting, wasting and underweight at each level. A stepwise manual backward elimination process was performed on covariates in the models. Factors with a $\mathrm{p}$ value of $<0.20$ were retained in the models. ${ }^{36}$ Only significant factors were reported ( $p$ value 0.05 ). The full models are provided in online supplementary material (tables 5-7). To measure the association of the explanatory variables on stunting, wasting and underweight, 
adjusted OR (aOR) with 95\% CI were calculated using the 'odds ratio' package in $\mathrm{R}^{37}$

\section{Patient and public involvement}

A community advisory committee approved the survey and advised on sampling principles. The results for the survey were disseminated through regional meetings which comprised of village leaders, government and stakeholders in each region. A comprehensive report on the survey results was provided to the Autonomous Region of Bougainville Government in 2018.

\section{Ethics approval}

The research project ethics approval was obtained by the University of Sydney Ethics Committee (Application Number: 2016/091) and the Autonomous Region of Bougainville Government.

\section{RESULTS}

\section{Sociodemographic characteristics of study population}

Over half the households (53.9\%) were in the North, $11.6 \%$ in Central and $34.5 \%$ in the South, reflecting the population density in each region. The Central region has a smaller population due to the remote, mountainous terrain and as a result of the civil war and migration associated with closure of Panguna mine. Over half (57.2\%) the households had five or less members. Most mothers were married or in a de facto relationship (93.6\%). The majority of mothers $(71.5 \%)$ and fathers $(70.1 \%)$ had primary level education, with a small percentage having no formal education (3\% mothers and 3.8\% fathers). Women mostly gave birth between the ages of 20 and 29 $(58.7 \%)$, with $8.4 \%$ giving birth before 20 years of age. Children had a mean age of 28.33 ( $\mathrm{SD} \pm 16.63$ ) months, with most children in the 24-29 months age category. There were slightly more male $(52.1 \%)$ than female $(47.9 \%)$ children in the study sample (table 2$)$. The sex ratio of male to female was 1.07 , which is consistent with previous studies. ${ }^{16}$

\section{Nutritional status of children under $\mathbf{5}$ years}

The overall nutritional status of children under 5 years is presented in table 3 . The low means for each of the nutrition indices indicate the study population has poorer nutrition outcomes compared with the WHO growth reference standards. Overall, $36.5 \%$ of children were stunted, $4.7 \%$ wasted and $15.9 \%$ underweight.

\section{Factors associated with stunting}

The null model shows that the MOR for VA was 1.59, when all factors were added into the model, the MOR decreased slightly, demonstrating the consistent role of VA in the model. Results showed that children living in households with unimproved toilets had greater odds of being stunted ( $\mathrm{aOR}=1.71,95 \%$ CI 1.14 to 2.55 ) compared with those households with improved toilet facilities. Maternal height was also a significant independent predictor of child stunting and the odds increased as
Table 2 Sociodemographic characteristics of study population

\begin{tabular}{|c|c|c|}
\hline Characteristics & $\begin{array}{l}\text { Frequency } \\
\text { (n) }\end{array}$ & Percentage (\%) \\
\hline \multicolumn{3}{|l|}{ Region } \\
\hline North & 595 & 53.9 \\
\hline Central & 128 & 11.6 \\
\hline South & 381 & 34.5 \\
\hline \multicolumn{3}{|l|}{ Wealth quintiles } \\
\hline Lowest & 214 & 19.4 \\
\hline Second & 220 & 19.9 \\
\hline Third & 242 & 21.9 \\
\hline Fourth & 229 & 20.7 \\
\hline Highest & 199 & 18.0 \\
\hline \multicolumn{3}{|l|}{ No. of household members } \\
\hline$\leq 5$ & 631 & 57.2 \\
\hline$>5$ & 473 & 42.8 \\
\hline \multicolumn{3}{|l|}{ Marital status } \\
\hline Married/de facto & 975 & 93.6 \\
\hline $\begin{array}{l}\text { Previously married } \\
\text { (divorced/widowed) }\end{array}$ & 49 & 4.7 \\
\hline Single & 18 & 1.7 \\
\hline \multicolumn{3}{|l|}{ Maternal education } \\
\hline Primary or lower & 748 & 71.5 \\
\hline High school or higher & 298 & 28.5 \\
\hline \multicolumn{3}{|l|}{ Paternal education } \\
\hline Primary or lower & 607 & 70.1 \\
\hline High school or higher & 259 & 29.9 \\
\hline \multicolumn{3}{|l|}{ Maternal age at birth } \\
\hline$>40$ years & 32 & 3.2 \\
\hline 30-39years & 294 & 29.7 \\
\hline 20-29years & 582 & 58.7 \\
\hline$<20$ years & 83 & 8.4 \\
\hline \multicolumn{3}{|l|}{ Child's sex } \\
\hline Female & 529 & 47.9 \\
\hline Male & 575 & 52.1 \\
\hline \multicolumn{3}{|l|}{ Child's age } \\
\hline Mean & & $28.33( \pm 16.63)$ \\
\hline $0-5$ months & 111 & 10.1 \\
\hline $6-23$ months & 347 & 31.4 \\
\hline 24-59 months & 646 & 58.5 \\
\hline
\end{tabular}

maternal height decreased. The odds of having a stunted child were 2.37 (95\% CI 1.29 to 4.35$)$ times higher among women measuring $<150 \mathrm{~cm}$ tall and $1.52(95 \%$ CI 1.02 to 2.26) times higher among women measuring $150-<155 \mathrm{~cm}$ tall compared with those women $\geq 155 \mathrm{~cm}$ tall (table 4$)$. 
Table 3 Prevalence of stunting, wasting and underweight in children $<5$ years

\begin{tabular}{|c|c|c|}
\hline Nutritional status & Mean ( $($ SD) & $\begin{array}{l}\text { Frequency, } \\
\text { n (\%) }\end{array}$ \\
\hline $\begin{array}{l}\text { Height-for-age Z score } \\
\text { (HAZ) }\end{array}$ & $-1.37( \pm 1.89)$ & \\
\hline Stunting (HAZ -2 SD) & & $368(36.5)$ \\
\hline $\begin{array}{l}\text { Weight-for-height Z score } \\
\text { (WHZ) }\end{array}$ & $0.00( \pm 1.28)$ & \\
\hline Wasting (WHZ -2 SD) & & $49(4.7)$ \\
\hline Weight-for-age Z score & $-0.80( \pm 1.41)$ & \\
\hline $\begin{array}{l}\text { Underweight (WAZ -2 SD) } \\
\text { (WAZ) }\end{array}$ & & $170(15.9)$ \\
\hline
\end{tabular}

\section{Factors associated with wasting}

No significant factors were found to be associated with wasting among the under-5 children in the multilevel mixed regression analysis. This is likely due to the small number of children who were wasted in the study sample $(\mathrm{n}=49)$. Maternal height between 150 and $<155 \mathrm{~cm}$ was borderline significant with a $\mathrm{p}$ value of 0.05 . The odds of a child being wasted was $2.17(1.00-4.74)$ times higher among women measuring 150 to $<155 \mathrm{~cm}$ compared with those $\geq 155 \mathrm{~cm}$. In the bivariate analysis, maternal height, birth order and child's age all reported a $p$ value of $<0.05$. We observed higher than expected numbers of wasted children in the shorter maternal height categories $(<155 \mathrm{~cm})$, younger children ( $0-5$ months, $6-23$ months) and among second and third born children.

\section{Factors associated with underweight}

The null model shows that the MOR for VA was 1.27, when all factors were added into the model, the MOR increased only slightly, demonstrating the consistent role of VA at each level. Poor drinking water, poor toilet facilities, child's age and birth order were all significant predictors for underweight in children under 5. Children from households with unimproved drinking water sources (aOR=1.97, 95\% CI 1.19 to 3.29) and unimproved toilet facilities ( $\mathrm{aOR}=2.11,95 \%$ CI 1.16 to 3.82 ) had a higher odds of being underweight. The odds of a child being underweight increased with birth order. The odds of underweight in third-born children was 6.77 (95\% CI 2.00 to 22.82) times the odds of first-born children and the odds of second-born children was 1.92 (95\% CI 1.09 to 3.36) times that of first-born children. Compared with children aged less than 6 months, children aged between $6-23$ months $(\mathrm{aOR}=4.83,95 \%$ CI 1.36 to 17.24) and 24-59 months (aOR=4.59, 95\% CI 1.29 to 16.26) were found to have a higher odds of being underweight (table 4).

\section{DISCUSSION}

This study assessed the nutritional status and factors associated with stunting, wasting and underweight from a sample of 1104 children under 5 years from cocoafarming communities in Bougainville. The analyses showed that $36.5 \%$ of children were stunted, $4.7 \%$ wasted and $15.9 \%$ underweight; results far higher than the WHO Western Pacific Region averages of $6.2 \%$ for stunting, $2.1 \%$ for wasting and $2.4 \%$ for underweight. ${ }^{38}$ Our study found that the odds of stunting increased significantly among children from households with unimproved toilet facilities, those born to mothers of shorter stature and children older than 6 months of age. The odds of a child being underweight was higher among children from households with unimproved toilet facilities, unimproved drinking water sources, children aged over 6 months and second-born and third-born children. In 2019, the ARoB voted overwhelmingly for independence from PNG. These findings provide an evidence base for relevant stakeholders and policymakers to support the development of interventions aimed at improving the nutrition and livelihoods of smallholder cocoa-farming families within Bougainville.

\section{Household characteristics}

Our analyses demonstrated that children from households with unimproved toilets had increased odds of being both stunted and underweight compared with those with improved toilets. A study in Timor Leste similarly found that children from households with flushable toilets had, on average, significantly higher height-for-age $\mathrm{Z}$ scores compared with those without. ${ }^{39}$ Households without access to clean water sources were also more likely to have an underweight child. These findings support research linking water and sanitation and child undernutrition in other places. ${ }^{40}$ Household environs, which include poor water and sanitation facilities and practices, in particular open defecation, increases the risk of infectious diseases and subsequently the uptake of nutrients from food. Persistent infections over time can lead to environmental enteric dysfunction (EED) which is thought to cause growth faltering in children due to chronic inflammation of the intestine and reduced nutrient absorption. ${ }^{41}$ The important role water, sanitation and hygiene (WaSH) play in child nutrition and development outcomes is of great importance for Bougainville where over two-thirds of households use unimproved toilets and one-third do not have safe drinking water.

While WaSH programmes have benefits, ${ }^{40} 42$ there remains uncertainty about the effectiveness of some of them. Three recent randomised controlled trials ${ }^{43-45}$ of WaSH interventions (water treatment, handwashing and sanitation) found limited effect on nutritional outcomes in high burden areas, leading to experts calling for more integrated 'Transformative WaSH' approaches that address the community-specific exposures and burden of EED. ${ }^{46}$ Our study area where $61 \%$ of people own livestock raises the potential dangers posed by animal faecal hazards. These findings provide the evidence supporting the ARoB Government strategic development plan 20182022, prioritising WaSH activities. 


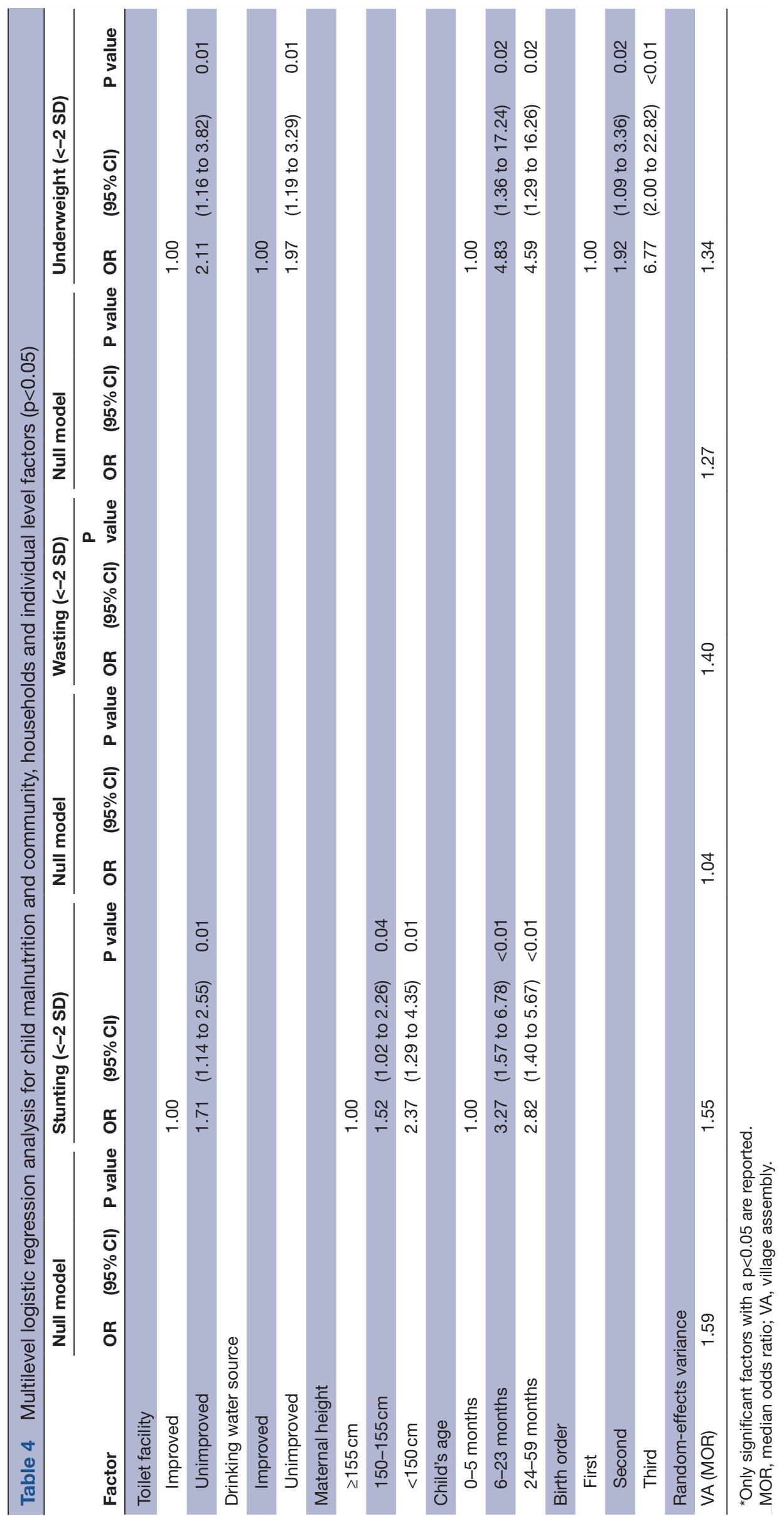

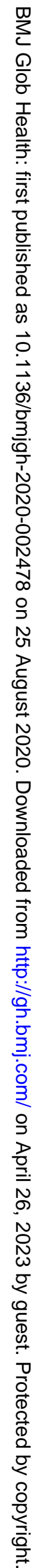




\section{Maternal characteristics}

Maternal height was a significant predictor of stunting and the odds of having a stunted child increased as maternal height decreased, a finding consistent with a number of studies from LMICs. ${ }^{48-50}$ Maternal stature is a combined indicator for both genetic and environmental stresses on a woman during the key growth years. Women of short stature have a higher risk of having a baby that is small-for-gestational age or low birth weight (LBW). These babies are at greater risk of infections and when infected do not absorb nutrients, leading to stunted growth. ${ }^{51}$ Risk of infection is higher in Bougainville where most households do not have adequate toilet facilities and sanitation. This intergenerational cycle of poor maternal nutrition and poverty ${ }^{52}$ was highlighted for action by the United Nations Standing Committee on Nutrition. ${ }^{53}$ Breaking this intergenerational cycle to ensure babies optimally grow requires specific interventions targeting women and children at critical life stages. Women during their adolescence and when pregnant are key periods for interventions, whereas for children, the first 1000 days of life are critical. ${ }^{54}$

\section{Child characteristics}

This study found an association between a child's age and stunting and underweight, with the odds of both stunting and underweight being highest in children aged 6-23 months. This could be attributed to feeding practices within the first 1000 days of life. Suboptimal breastfeeding and inappropriate offering of solid foods is associated with poor nutrition outcomes in children. ${ }^{48}$ The recent DHS conducted in PNG found the median duration for exclusive breastfeeding in the islands region was 4.6 months, with only $20.6 \%$ of children aged $6-59$ months receiving the minimum acceptable diet. ${ }^{55}$ Poor diet quality among children is a key concern for the Pacific Region. ${ }^{7}$

Birth order was also significantly associated with a child being underweight and the odds of a child being underweight increased with birth order. This finding is consistent with other studies that have found children born later to be susceptible to poorer nutrition and health outcomes. ${ }^{56-58}$ One explanation for this could be that increasing numbers of children within a household puts strain on food and household resources, impacting the level of care and nutrition provided ${ }^{59}$ These findings emphasise the importance of family planning and reproductive health services that enable women to control when and how many children they have.

\section{Strengths and limitations}

This study is the largest nutrition study to be completed in the ARoB to date and provides essential data for the ARoB, PNG and the greater Western Pacific Region, where undernutrition remains a high burden. The study applies robust statistical methods to assess factors associated with poor nutrition in children. Some limitations include the use of cross-sectional data, from which causal inferences cannot be drawn. The smaller sample size also restricted the analysis for wasting. The information used for this study was based on mothers' recall ability. We had originally planned to include dietary diversity (a known contributor to child nutrition); however, the data collected were not valid due to inconsistencies which were identified during further qualitative research conducted in the study villages.

\section{CONCLUSION}

The findings demonstrate a high prevalence of undernutrition, specifically stunting, among Bougainville cocoafarming households. Factors found to be significantly associated with poor nutrition outcomes in children under five are unsafe drinking water and sanitation, maternal height, birth order and age of the child. These findings reinforce the multidimensional nature of undernutrition and the need for interdisciplinary approaches to address it. Sustained improvements to undernutrition and the livelihoods of cocoa-farming communities in the ARoB cannot be achieved without interventions that simultaneously target key life stages for women and children and the underlying social and environmental factors. The long-term consequences of undernutrition are costly due to losses in human productivity, losses from poor cognitive development and reduced schooling, and losses due to increased healthcare costs. These findings provide a much-needed evidence base for future programmes and policy decisions on Bougainville's journey to independence.

\section{Twitter Merrilyn Walton @merrilyn_walton}

Acknowledgements Thank you to Mr James Butubu, Dr Josephine Saul-Maora, $\mathrm{Dr}$ John Konan, Mr Clement Totavun and Mr Sam Rangai for their contributions to the success of the survey. We thank Dr Tanvir Huda, Mr Grant Vinning, Dr Grant Hill-Cawthorne for their comments about the nutrition questions in the survey and the draft article.

Contributors All authors made substantial contributions to the conception and design of the research. JH was the lead author of the manuscript. All authors were involved in critically revising the intellectual content of the manuscript. All authors agreed to be accountable for all aspects of the work. JH: writing of the original draft preparation, review and editing, formal analysis, visualisation, investigation and software. MW: conceptualisation, methodology, writing of the original draft, review and editing, and investigation. FVO: formal analysis, writing of the original draft preparation, visualisation and data presentation. DG: conceptualisation, methodology, writing, review and editing, investigation and funding acquisition. KB: conceptualisation, writing, review and editing, and investigation. JB: writing, review and editing.

Funding This research project is supported by the Australian Centre for International Agricultural Research (ACIAR) (HORT/2014/094).

\section{Competing interests None declared.}

Patient and public involvement Patients and/or the public were involved in the design, or conduct, or reporting or dissemination plans of this research. Refer to the Methods section for further details.

Patient consent for publication Not required.

Ethics approval The research project was approved by the University of Sydney Ethics Committee (Application Number: 2016/091) and the Autonomous Region of Bougainville Government. Participants were provided with detailed information about the project prior to commencing the survey and were informed that their 
participation was voluntary and that they could choose to withdraw at anytime. Informed consent was obtained from all individual respondents or caregivers for children under the age of 16 at the time of survey.

Provenance and peer review Not commissioned; externally peer reviewed.

Data availability statement All data relevant to the study are included in the article or uploaded as supplementary information. The data are stored on a University encrypted server. All data are deidentified prior to use.

Open access This is an open access article distributed in accordance with the Creative Commons Attribution Non Commercial (CC BY-NC 4.0) license, which permits others to distribute, remix, adapt, build upon this work non-commercially, and license their derivative works on different terms, provided the original work is properly cited, appropriate credit is given, any changes made indicated, and the use is non-commercial. See: http://creativecommons.org/licenses/by-nc/4.0/.

\section{ORCID iDs}

Jessica Hall http://orcid.org/0000-0002-9438-0651

Justin Beardsley http://orcid.org/0000-0003-1978-1559

\section{REFERENCES}

1 Fanzo J, Hawkes C, Udomkesmalee E, et al. 2018 global nutrition report: shining a light to Spur action on nutrition, 2018.

2 Grantham-McGregor S, Cheung YB, Cueto S, et al. Developmental potential in the first 5 years for children in developing countries. Lancet 2007;369:60-70.

3 Wu G, Imhoff-Kunsch B, Girard AW. Biological mechanisms for nutritional regulation of maternal health and fetal development. Paediatr Perinat Epidemiol 2012;26 Suppl 1:4-26.

4 WHO. Global nutrition targets 2025 policy brief series (WHO/NMH/ NHD/14.2). Geneva: World Health Organization, 2014.

5 United Nations (DESA). Transforming our world: the 2030 agenda for sustainable development, 2016.

6 UNICEF (United Nations Children's Fund). Improving child nutrition: the achievable imperative for global progress. New York: UNICEF, 2013.

7 FAO, UNICEF, WFP. Placing nutrition at the centre of social protection. Asia and the Pacific regional overview of food security and nutrition 2019. Bangkok: FAO, 2019.

8 UNICEF. The State of the World's Children 2019. Children, Food and Nutrition: Growing well in a changing world. New York: UNICEF, 2019.

9 McGlynn PJ, Renzaho Andre $\mu \mathrm{N}$, Pham MD, et al. Critical examination of evidence for the nutritional status of children in Papua New Guinea - a systematic review. Asia Pac J Clin Nutr 2018;27:1.

10 National Statistical Office PNG. 2011 national population and housing census of Papua New Guinea, 2011.

11 Walton M, Hall J, Van Ogtrop F, et al. The extent to which the domestic conditions of cocoa farmers in Bougainville impede livelihoods. One Health 2020;10:100142.

12 Spears D. How much international variation in child height can sanitation explain? The World Bank, 2013.

13 Walton M, Guest D, Vinning G. Improving the Livelihood of farmers in Bougainville. In: Walton M, ed. One planet one health. Sydney University Press, 2019: 127-41.

14 Anderman TL, Remans R, Wood SA, et al. Synergies and tradeoffs between cash crop production and food security: a case study in rural Ghana. Food Secur 2014;6:541-54.

15 Agbo A, Kouamé C, N'Doua N, et al. Assessment of cocoa producers' children nutritional status in the Nawa region, Co'te d'Ivoire. J Food Nutr Res 2017;5:606-13.

16 Schmidt EG, Holtemeyer Rachel;, Rosenbach Brian;, et al. Papua New Guinea survey report: rural household survey on food systems. Washington, DC: International Food Policy Research Institute (IFPRI), 2019.

17 Toribio J-A, Markham R, Carter L, et al. Research for development to improve health outcomes from agriculture for rural communities: what is needed? Food Security 2018;10:661-75.

18 Arsyad DS, Nasir S, Arundhana Al, et al. A one health exploration of the reasons for low cocoa productivity in West Sulawesi. One Health 2019;8:100107.

19 Ngure FM, Humphrey JH, Mbuya MNN, et al. Formative research on hygiene behaviors and geophagy among infants and young children and implications of exposure to fecal bacteria. Am J Trop Med Hyg 2013;89:709-16.
20 Hill-Cawthorne GA. One Health/Eco Health/Planetary Health and their evolution. In: Walton M, ed. One planet one health. Sydney: University of Sydney Press, 2019: 1-21.

21 Walton M, Hall J, Guest D, et al. Applying one health methods to improve cocoa production in Bougainville: a case study. One Health 2020;10:100143

22 Pinstrup-Andersen P. Agricultural research and policy for better health and nutrition in developing countries: a food systems approach. Agricultural Economics 2007;37:187-98.

23 Hurney M. Short changed: the human and economic cost of child undernutrition in Papua New Guinea. Sydney, Australia: Save the Children, 2017

24 Hou X. Stagnant stunting rate despite rapid economic Growth-An analysis of cross sectional survey data of undernutrition among children under five in Papua New Guinea. AIMS Public Health 2016;3:25-39.

25 Bauze AE, Tran LN, Nguyen K-H, et al. Equity and geography: the case of child mortality in Papua New Guinea. PLoS One 2012; 7:e37861.

26 Wand $\mathrm{H}$, Lote $\mathrm{N}$, Semos I, et al. Investigating the spatial variations of high prevalences of severe malnutrition among children in Papua New Guinea: results from geoadditive models. BMC Res Notes 2012:5:228

27 Olita'a D, Vince J, Ripa P, et al. Risk factors for malnutrition in children at Port Moresby General Hospital, Papua New Guinea: a case-control study. J Trop Pediatr 2014;60:442-8.

28 Gibson J. Can women's education aid economic development? The effect on child stunting in Papua New Guinea, 2019.

29 King SE, Nicholas Mascie-Taylor CG. Nutritional status of children from Papua New Guinea: associations with socioeconomic factors. Am J Hum Biol 2002;14:659-68.

30 van der Meulen Rodgers Y, Kassens AL. Women's asset ownership and children's nutritional status: evidence from Papua New Guinea. Soc Sci Med 2018;204:100-7.

31 WHO. Who child growth standards: length/height-for-age, weightfor-age, weight-for-length, weight-for-height and body mass indexfor-age: methods and development, 2006.

32 De Onis M, Blössner M, World Health Organization, Programme of N. WHO global database on child growth and malnutrition / compiled by Mercedis de Onis and Monika Blössner. Geneva: World Health Organization, 1997

33 Filmer D, Pritchett LH. Estimating wealth effects without expenditure data--or tears: an application to educational enrollments in states of India. Demography 2001;38:115-32.

34 Coates J, Swindale A, Bilinsky P. Household food insecurity access scale (HFIAS) for measurement of food access: indicator guide. Washington, DC: food and nutrition technical assistance project, academy for educational Development, 2007: 34.

35 Organization WH. Core questions on drinking water and sanitation for household surveys. World Health Organization, 2006

36 Akombi BJ, Agho KE, Merom D, et al. Multilevel analysis of factors associated with wasting and underweight among children under-five years in Nigeria. Nutrients 2017;9:44.

37 Schratz P. R package 'oddsratio': Odds ratio calculation for $G A M(M)$ s \& $G L M(M)$ s, version: 1.0.2, 2017.

38 Global Health Observatory visualization JcmeU-W-W. Regional prevalence and numbers of stunting, underweight and wasting (1990-2019, 2019.

39 Spencer PR, Sanders KA, Canisio Amaral P, et al. Household resources and seasonal patterns of child growth in rural Timor-Leste. Am J Hum Biol 2017;29:e22916.

40 Fink G, Günther I, Hill K. The effect of water and sanitation on child health: evidence from the demographic and health surveys 19862007. Int J Epidemiol 2011;40:1196-204.

41 Harper KM, Mutasa M, Prendergast AJ, et al. Environmental enteric dysfunction pathways and child stunting: a systematic review. PLoS Negl Trop Dis 2018;12:e0006205.

42 Dangour AD, Watson L, Cumming O, et al. Interventions to improve water quality and supply, sanitation and hygiene practices, and their effects on the nutritional status of children. Cochrane Database Syst Rev 2013:CD009382.

43 Humphrey JH, Mbuya MNN, Ntozini R, et al. Independent and combined effects of improved water, sanitation, and hygiene, and improved complementary feeding, on child stunting and anaemia in rural Zimbabwe: a cluster-randomised trial. Lancet Glob Health 2019;7:e132-47.

44 Null C, Stewart CP, Pickering AJ, et al. Effects of water quality, sanitation, handwashing, and nutritional interventions on diarrhoea and child growth in rural Kenya: a cluster-randomised controlled trial. Lancet Glob Health 2018;6:e316-29. 
45 Luby SP, Rahman M, Arnold BF, et al. Effects of water quality, sanitation, handwashing, and nutritional interventions on diarrhoea and child growth in rural Bangladesh: a cluster randomised controlled trial. Lancet Glob Health 2018;6:e302-15.

46 Prendergast AJ, Gharpure R, Mor S, et al. Putting the "A" into WaSH: a call for integrated management of water, animals, sanitation, and hygiene. Lancet Planet Health 2019;3:e336-7.

47 Cumming O, Arnold BF, Ban R, et al. The implications of three major new trials for the effect of water, sanitation and hygiene on childhood diarrhea and stunting: a consensus statement. BMC Med 2019;17:1-9.

48 Black RE, Victora CG, Walker SP, et al. Maternal and child undernutrition and overweight in low-income and middle-income countries. Lancet 2013;382:427-51.

49 Khatun W, Alam A, Rasheed S, et al. Exploring the intergenerational effects of undernutrition: association of maternal height with neonatal, infant and under-five mortality in Bangladesh. BMJ Glob Health 2018;3:e000881.

50 Özaltin E, Hill K, Subramanian SV. Association of maternal stature with offspring mortality, underweight, and stunting in low- to middleincome countries. JAMA 2010;303:1507-16.

51 Kozuki N, Katz J, Lee A, et al. Short maternal stature increases the risk of small-for-gestational-age and preterm births in low-and middle-income countries: individual participant data meta-analysis and population attributable fraction 2015.

52 Khatun W, Rasheed S, Alam A, et al. Assessing the intergenerational linkage between short maternal stature and Under-Five stunting and wasting in Bangladesh. Nutrients 2019;11:1818.
53 United Nations Standing Committee on Nutrition. 6th report on the world nutrition situation: progress in nutrition. Geneva: UNSCN, 2010.

54 Vaivada T, Gaffey MF, Das JK, et al. Evidence-Based interventions for improvement of maternal and child nutrition in lowincome settings: what's new? Curr Opin Clin Nutr Metab Care 2017;20:204-10.

55 National Statistical Office (NSO) [Papua New Guinea], ICF. Papua New Guinea demographic and health survey 2016-18. Port Moresby, Papua New Guinea, and Rockville, Maryland, USA: NSO and ICF, 2019.

56 Modin B. Birth order and mortality: a life-long follow-up of 14,200 boys and girls born in early 20th century Sweden. Soc Sci Med 2002;54:1051-64.

57 Tariq J, Sajiad A, Zakar R, et al. Factors associated with undernutrition in children under the age of two years: secondary data analysis based on the Pakistan demographic and health survey 2012-2013. Nutrients 2018;10:676.

58 Huey SL, Finkelstein JL, Venkatramanan S, et al. Prevalence and correlates of undernutrition in young children living in urban slums of Mumbai, India: a cross sectional study. Front Public Health 2019;7:191.

59 Bishwakarma R, Villa KM. First come, first served? Birth order effects on child height in South Africa. J Demogr Economics 2019;85:71-94. 